benefit for patients with an increased risk for degeneration of the valves. At present it is impossible to assess prospectively which patients are at risk for immunemediated valve degeneration. However, children listed for retransplantation for reasons other than technical failure and children with preformed HLA antibodies are likely candidates. We recommend that for these patients at "high risk" a crossmatch-negative, HLA-matched heart valve allograft be selected.

The cooperation of the Stichting Rode Kruis Bloedbank Noord Nederland, their blood donors, and Bio Implant Services for providing the HLA types of the donors is gratefully acknowledged.

\section{REFERENCES}

1. Clarke DR, Campbell DN, Hayward AR, Bishop DA. Degeneration of aortic valve allografts in young recipients. J Thorac Cardiovasc Surg 1993;105:934-42.

2. Yankah AC, Wottge HU, Muller-Hermelink HK, et al. Transplantation of aortic and pulmonary allografts, enhanced via- bility of endothelial cells by cryopreservation, importance of histocompatibility. J Card Surg 1987;2(suppl):209-20.

3. Hoekstra F, Knoop C, Jutte N, et al. Effect of cryopreservation and HLA-DR matching on the cellular immunogenicity of human cardiac valve allografts. J Heart Lung Transplant 1994:13:1095-8.

4. Zhao XM, Green M, Frazer IH, Hogan P, O'Brien MF. Donor-specific immune response after aortic valve allografting in the rat. Ann Thorac Surg 1994;57:1158-63.

5. Smith JD, Ogino H, Hunt D, Laylor RM, Rose ML, Yacoub MH. Humoral immune response to human aortic valve homografts. Ann Thorac Surg 1995;60:S127-30.

6. Scornic JC, Pfaff WW, Howard RJ, et al. Increased antibody responsiveness to blood transfusions in pediatric patients. Transplantation 1994;58:1361-5.

7. Yankah AC, Wottge HU, Muller-Ruchoitz W. Short-course cyclosporin a therapy for definite allograft valve survival immunosuppression in allograft valve operations. Ann Thorac Surg 1995;60:146-50.

8. Sanfilippo F, MacQueen JM, Vaughn WK, Foulks GN. Reduced graft rejection with good HLA-A and B matching in high-risk corneal transplantation. N Engl J Med 1986;315:29-35.

\title{
MULTIPLE EPISODES OF THROMBOSIS WITH BIVENTRICULAR SUPPORT DEVICES WITH INADEQUATE ANTICOAGULATION AND EVIDENCE OF ACCELERATED INTRAVASCULAR COAGULATION
}

George J. Despotis, MD, Vladimir Levine, MD, PhD, Heinrich Joist, MD, PhD, Samuel A. Santoro, MD, PhD, and Eric Mendeloff, MD, St. Louis, Mo.

Ventricular assist devices (VADs) may induce complex hemostatic abnormalities mediated by excessive activation of platelets, coagulation, and fibrinolysis with resulting consumption of platelets and labile coagulation factors and sometimes associated with thrombosis. ${ }^{1-3}$ We describe the case of a teenaged boy with

From the Departments of Anesthesiology, Internal Medicine, Pathology, and Surgery, Washington University School of Medicine, and the Departments of Internal Medicine and Pathology, St. Louis University School of Medicine, St. Louis, Mo.

Supported in part by a research grant from ABIOMED, INC.

Received for publication August 9, 1996; accepted for publication Sept. 12, 1996.

Address for reprints: George Despotis, MD, Division of Cardiothoracic Anesthesiology, Department of Anesthesiology, Box 8054, Washington University School of Medicine, 660 South Euclid Ave., St. Louis, MO 63110.

J Thorac Cardiovasc Surg 1997;113:419-22

Copyright $(\mathcal{C} 1997$ by Mosby-Year Book, Inc.

$0022-5223 / 97 \$ 5.00+0 \quad \mathbf{1 2 / 5 4 / 7 8 0 3 1}$ dilated cardiomyopathy whose course was initially complicated by excessive bleeding. He subsequently had multiple episodes of thrombosis of biventricular assist devices (BVADs) that were associated with accelerated intravascular coagulation temporally related to suboptimal warfarin anticoagulation.

A 15-year-old boy with Becker's muscular dystrophy was admitted for treatment of progressive congestive heart failure. Transthoracic echocardiography revealed dilated cardiomyopathy with severely reduced ejection fraction and a right ventricular mural thrombus. Over a 3-week period after admission, he began having increasingly severe symptoms of congestive heart failure with respiratory distress and profound hypotension. The symptoms were unresponsive to aggressive medical management with inotropic support, diuresis, afterload reduction, and intraaortic balloon counterpulsation. After the development of cardiogenic shock, ABIOMED BVADs (ABIOMED Cardiovascular, Inc., Danvers, Mass.) were implanted as a bridge to transplantation (day 1). The patient was given a continuous infusion of heparin at a rate of 1500 to $2200 \mathrm{U} / \mathrm{hr}$ to maintain the celite activated clotting time between 180 and 200 seconds. While he was 

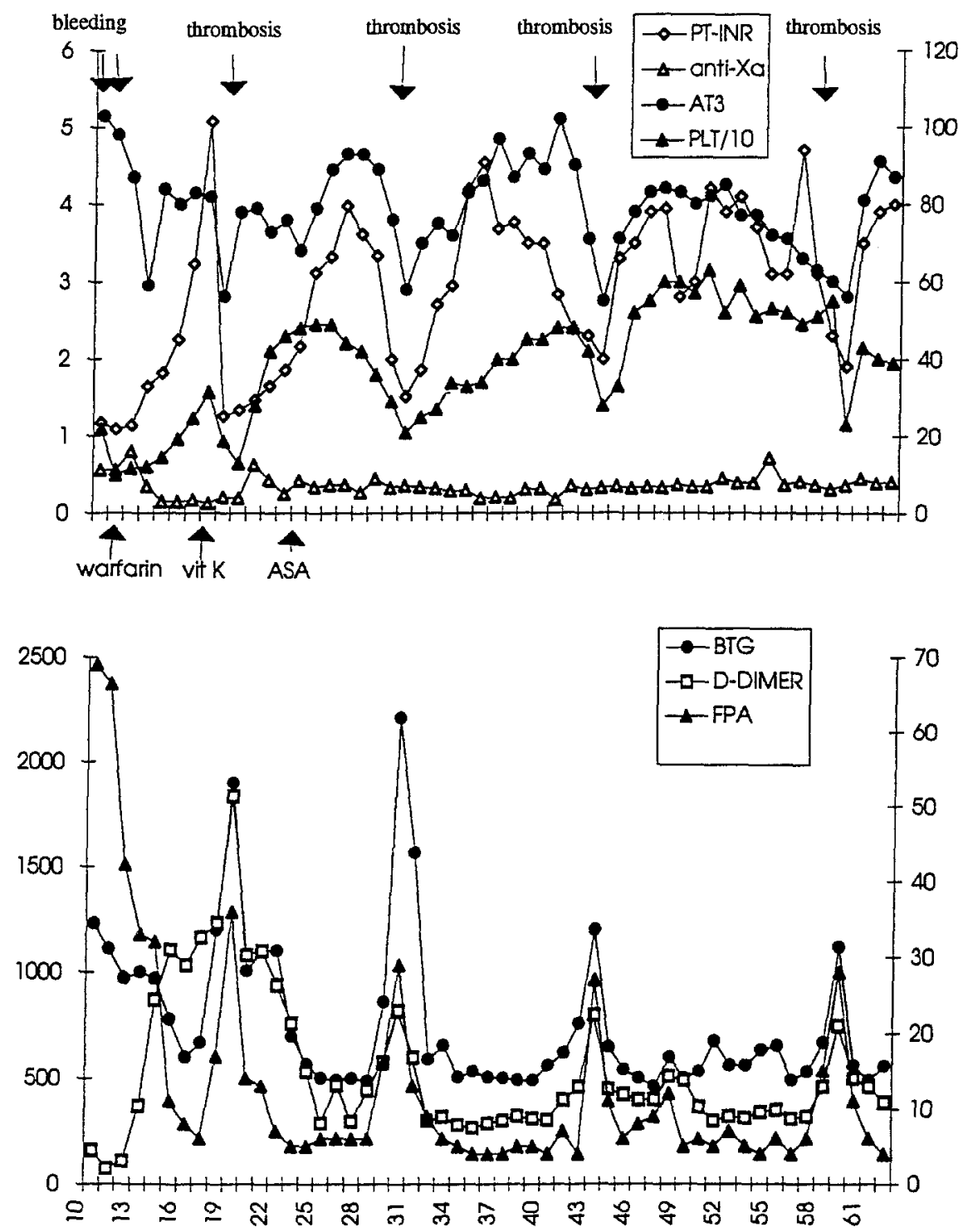

Fig. 1. Alterations in hemostatic measurements and heparin concentrations during hospitalization days 8 to 80 in relation to abnormal bleeding and VAD thrombosis in a patient with BVADs for heart failure caused by cardiomyopathy. Top left ordinate, Prothrombin international normalized ratio (PT-INR) and anti-factor Xa heparin concentration (anti-Xa) (U/ml). Top right ordinate, Antithrombin III $(A T 3)(\mathrm{U} / \mathrm{ml})$ and platelet count $(P L T / 10)$ (thousands/ $\mu \mathrm{l} / 10)$. Bottom left ordinate, $\beta$-thromboglobulin $(B T G)(\mathrm{IU} / \mathrm{ml})$ and fibrin degradation products in D-dimer $(\mathrm{ng} / \mathrm{ml})$. Bottom right ordinate, Fibrinopeptide A (FPA) $(\mathrm{ng} / \mathrm{ml})$; $A S A$, aspirin; vit $K$, vitamin $\mathrm{K}(1 \mathrm{mg})$.

receiving antifibrinolytic therapy (epsilon-aminocaproic acid), heparin anticoagulation, and transfusion of fresh frozen plasma and platelet concentrates, his initial course (days 1 to 8 ) was complicated by recurrent episodes of severe bleeding that necessitated exploration on five occasions. No surgical source of bleeding could be identified, yet clots were visible in the BVAD system. Informed consent was obtained, and blood specimens were collected daily for a more detailed evaluation of the patient's coagulation status. Sensitive markers of activation of platelets, coagulation, and fibrinolysis were used for these evaluations (Fig. 1). Shortly after heparin was supplemented with warfarin on the basis of a presumptive diagnosis of consumptive coagulopathy caused by inadequate anticoagulation, the excessive bleeding stopped. Despite warfarin anticoagulation to maintain the pro- 
thrombin time international normalized ratio (PT-INR) at 2 to 3 and therapeutic blood heparin concentrations (anti-factor Xa, $0.35 \pm 0.02 \mathrm{U} / \mathrm{ml}$; anti-factor IIa, $0.42 \pm$ $0.04 \mathrm{U} / \mathrm{ml}$ ), the patient began having recurrent thrombosis of the BVAD system, necessitating device replacement (Fig. 1, top). The initial episode of BVAD thrombosis was temporally related to reversal of warfarin with intravenous vitamin $\mathrm{K}$, which was administered because of a progressive and persistent elevation in the PT-INR. Subsequently, heparin-induced thrombocytopenia was ruled out by means of a serotonin-release assay, along with deficiency of either protein $\mathrm{C}$ or $\mathrm{S}$, and aspirin was added to the anticoagulation regimen. The four subsequent episodes of BVAD thrombosis were also temporally related to the intensity of warfarin anticoagulation, specifically with INRs below 2.5 (see Fig. 1). In addition, INRs were related directly to platelet counts $(r=0.53, p<0.0001)$ and indirectly to $\beta$-thromboglobulin $(\mathrm{BTG})\left(r^{*}=-0.64, p<0.0001\right)$ and fibrinopeptide A (FPA) $(r=-0.66, p<0.0001)$ (Fig. 2). Platelet counts were also indirectly related to FPA values $(r=-0.60$, $p<0.0001)$. The considerable fluctuations in INRs may have been related to the patient's fluctuating nutritional status (vitamin $\mathrm{K}$ intake), which was affected by periodic requirements for mechanical ventilatory support. The patient underwent successful heart transplantation on day 80 and was discharged without evidence of transient ischemic attacks or strokes after an uneventful postoperative course.

Activation of platelets and the intrinsic and extrinsic coagulation pathways by VADs can result in bleeding ${ }^{3,4}$ or thrombotic complications (or both) ${ }^{1-3}$ Heparin anticoagulation is frequently used to prevent excessive hemostatic system activation and thrombosis with VADs because its anticoagulant effect can be rapidly reversed, which may be necessary when frequently encountered ${ }^{4}$ bleeding complications occur. However, the optimal therapeutic doses for heparin anticoagulation with VADs have not been well defined. In addition, heparin anticoagulation does not adequately suppress excessive thrombin generation during extracorporeal circulation, nor does it necessarily prevent thrombosis, as previously described in a patient with end-stage cardiomyopathy who required ABIOMED BVADs. ${ }^{2}$ Our findings indicate that the multiple episodes of thrombosis in this patient may have been related to an underlying state of excessive hemostatic system activation, caused at least in part by inadequate anticoagulation, as demonstrated by (1) a dose-time association between reduced INR and thrombotic events and (2) a time association between thrombotic events and elevations of FPA, D-dimers, and BTG with a concurrent decreases in platelet count and antithrombin III. Furthermore, sensitive markers of platelet and coagulation activation were markedly increased when INRs were below 2.5 (Fig. 2). Platelet counts, which have previously been shown to be associated with an increased risk of thrombus formation, ${ }^{1}$ correlated with INRs and were indirectly related to FPA in the present study. This observation suggests that thrombin may have partially mediated activation and consumption of platelets. Thus our findings support previous suggestions ${ }^{3}$

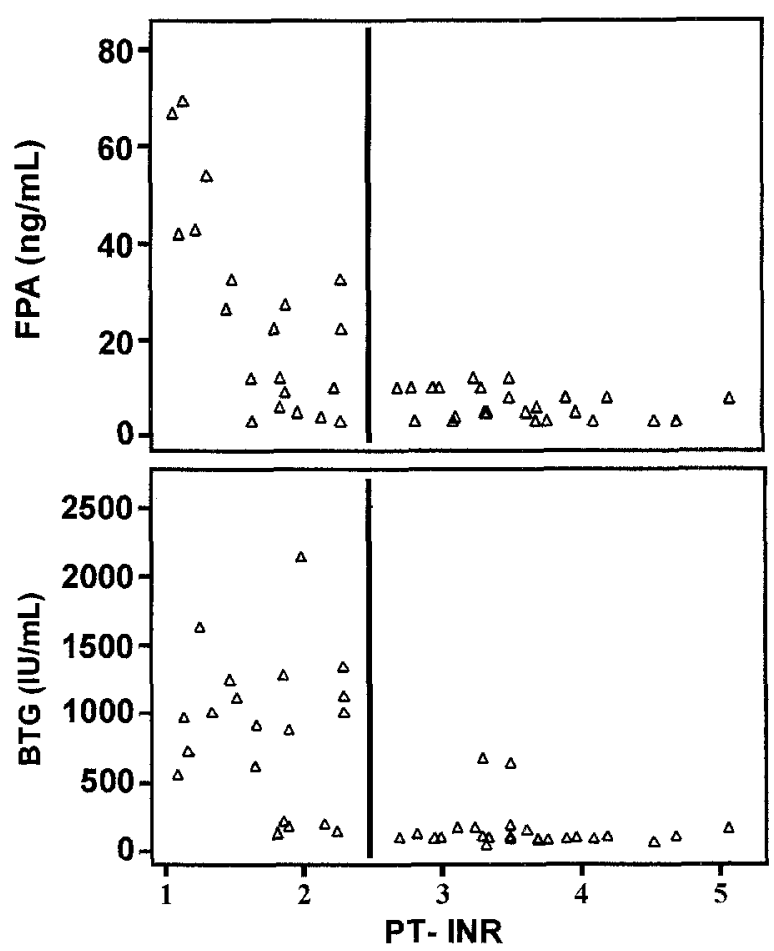

Fig. 2. Relations between fibrinopeptide A (FPA) (upper panel) and $\beta$-thromboglobulin (BTG) (lower panel) and PT-INR. Vertical line demarcates an INR of 2.5 .

that a greater degree of warfarin anticoagulation (INR 2.5 to 3.5 ) may be required to prevent thrombosis with VADs. It is of interest that the patient's excessive bleeding subsided within the first 2 days after initiation of warfarin therapy. This effect may have been related to further suppression of the consumptive state. The concept of enhanced anticoagulation resulting in better preservation of hemostasis and reduced bleeding is supported by recent findings, which demonstrate that maintenance of higher, patient-specific heparin concentrations during extracorporeal circulation can reduce consumption of coagulation factors by better suppression of thrombin activity. ${ }^{5}$ Further prospective studies are needed for several reasons: (1) to determine more accurately the incidence of abnormal bleeding and thrombosis with VADs, (2) to characterize the therapeutic range for warfarin anticoagulation with VADs and determine if a specific INR (e.g., 2.5) is optimal for reducing thrombotic complications and suppressing platelet and coagulation activation using sensitive biochemical markers in a series of patients supported with VADs, and (3) to evaluate alternate forms of singleagent or combined antithrombotic therapy, such as reversible, specific inhibition of thrombin and platelets, as well as antithrombin III supplementation and/or use of heparin-bound extracorporeal circuits. 


\section{REFERENCES}

1. Sato N, Mohri H, Fujimasa I, et al. Multivariate analysis of risk factors for thrombus formation in University of Tokyo ventricular assist device. J Thorac Cardiovasc Surg 1993;106:520-7.

2. Despotis GJ, Levine V, Alsoufiev A, Joist J, Goodnough LT, Pasque M. Recurrent thrombosis of biventricular support devices associated with accelerated intravascular coagulation and increased heparin requirements. J Thorac Cardiovasc Surg 1996;112:538-40.
3. Copeland JG III. Thromboembolism and bleeding: clinical strategies. Ann Thorac Surg 1996;61:376-7.

4. Bartlett RH. Extracorporeal life support for cardiopulmonary failure. Curr Prob1 Surg 1990;27:621-705.

5. Despotis GJ, Joist JH, Hogue CW, et al. More effective suppression of hemostatic system activation in patients undergoing cardiac surgery by heparin dosing based on heparin blood concentrations rather than ACT. Thromb Haemostas 1996;76: 902-8. 